\title{
Tendências do ajuste macroeconômico global
}

João Basilio Pereima*

RESUMO - Este artigo analisa a tendência do processo de ajuste macroeconômico e estrutural da economia mundial a ser conduzido pelos países industrializados e emergentes. Os primeiros para recuperar suas economias e os grandes desequilíbrios acumulados nas últimas décadas, e os segundos para continuar crescendo e avançando tecnologicamente. $\mathrm{O}$ Artigo adverte para os riscos incorridos pelo Brasil, caso persista em seu ritmo leniente e tímido do seu programa de desenvolvimento econômico, se é que existe um de fato.

\section{INTRODUÇÃO}

A era que marca a primeira década do século XXI poderá ir para história, talvez, como um período que marcou o fim de um grande ciclo do desenvolvimento do sistema capitalista mundial. Não propriamente pelo desmonte de uma grande pirâmide especulativa e seu alastramento para a economia real dos países industrializados, mas pela exaustão de um padrão de desenvolvimento econômico e coordenação financeira mundial. O ciclo atual se iniciou em 1971 e terminará em 2010, trinta e nove anos depois, uma duração maior que o conturbado e perigoso ciclo anterior de Bretton Woods, que durou vinte e três anos de 1948 até 1971.

Do ponto de vista macroeconômico, o ciclo atual é caracterizado pela flutuação das moedas soberanas, por mobilidade intensa de capital, por um sistema monetário internacional uninacional (hegemonia do dólar) e pelo enorme desajuste da poupança mundial, o qual combinou de forma insustentável no longo prazo, elevados superávits de um lado e elevados déficits de outro, numa relação simbiótica entre poucos países que agora está chegando ao fim.

Do ponto de vista político, o ciclo de expansão capitalista é comumente interpretado como um ciclo de retorno ao liberalismo, muito embora, como mostraremos e argumentaremos, esta é uma concepção incompleta e até mesmo errônea para caracterizar o período. O Estado, mesmo quando privatizou, terceirizou atividades e devolveu a regulação da ordem econômica ao mercado, nunca esteve tão ativo. Basta verificar a alta relação orçamento/PNB de vários países, mesmo os países ditos liberais como EUA e Reino Unido.

\footnotetext{
* Doutorando do Programa de Pós-Graduação em Desenvolvimento Econômico da UFPR e Professor
} Assistente do Departamento de Economia da mesma instituição. Endereço eletrônico: joaobasilio@ufpr.br. 
O fim do longo ciclo de expansão capitalista mundial remodelou a economia mundial estabelecendo novas relações de forças, as quais estão em pleno florescimento. $\mathrm{O}$ FMI estimou que os países pobres, que representavam 37\% do PIB mundial de US\$ 41 trilhões em 2000, poderão chegar a 51\% de um PIB de US\$ 89 trilhões em 2014 (IMF, 2009). $\mathrm{O}$ atual momento funde a turbulência conjuntural a uma mudança estrutural na economia mundial.

Nas próximas seções deste artigo, pretendemos abordar vários aspectos que consideramos importantes para traçar um quadro de tendências para a economia mundial e para o Brasil. O risco de realizar incursões no incerto e turvo futuro pode ser suportado por todos, se pensarmos mais em termos de cenários possíveis do que em previsões determinísticas. Assim ao tratarmos de tendências, pedimos ao leitor que interprete o termo no seu sentido exploratório, de quem descreve um cenário possível, e não de quem apenas conta uma história previamente conhecida e cujo roteiro e capítulo final já estão escritos. Como em economia o átomo pensa, e toma decisões, nada é verdadeiramente certo no futuro.

\section{A CORREÇÃO DO DESEQUILÍBRIO DA POUPANÇA EXTERNA}

O longo ciclo de expansão capitalista pós 1971 pode ser caracterizado por um padrão de financiamento baseado num sistema binário, gravitando um corpo em redor do campo gravitacional do outro. Um centro é formado por países com elevados superávits em transações correntes, que em termos de contabilidade macroeconômica significa geração de poupança externa, e o outro centro é formado por países com elevados déficits em transações correntes, que significa despoupança externa. Os países deficitários em transações correntes compram vultosos volumes de produtos dos países superavitários, viabilizando assim o modelo de crescimento baseado em exportações destes últimos. Como os países deficitários estão consumindo no agregado mais que sua renda interna eles compram dólares para realizar suas compras na economia mundial, que por enquanto é a principal moeda de troca internacional. No caso dos EUA, ele apenas emite os dólares de que necessita. Além disto, os governos deficitários também emitem títulos da dívida pública, uma parte para esterilizar a liquidez interna gerada pela emissão de moeda e outra parte para equilibrar seus balanços de pagamentos deficitários. Para isso, abrem a conta de capital permitindo a entrada de capital especulativo para compra de títulos do governo. Em última instância, tomando o caso da principal economia, os EUA, os dólares remetidos para pagar as compras baratas feitas nos países asiáticos (as quais geram déficits comerciais), retornam na forma de investimento de 
fundos soberanos para comprar títulos da dívida pública americana equilibrando assim seu balanço de pagamentos. A China Investment Corporate-CIC administra um fundo soberano com mais de US\$2,0 trilhões de saldo, dos quais boa parte está aplicado em títulos americanos. Esta simbiose apenas se mantém enquanto o país deficitário é capaz de se endividar e atrair capital financeiro para manter o equilíbrio do balanço de pagamentos. O esquema é semelhante a um mecanismo Ponzi-devedor, sustentado por outro Ponzi-credor ${ }^{1}$.

Em toda a história econômica mundial, ocorreram vários episódios em que países incapazes de rolar suas dívidas decretaram moratória (default), ou que ainda rolam indefinidamente suas altíssimas dívidas, como vem fazendo Japão e Itália. Estes casos podem ser interpretados como um esquema de financiamento Ponzy. Como são paises devedores podemos dizer que são Ponzy-devedores. O caso Chinês/Asiático é único na história da economia, por reproduzir um esquema Ponzy pelo lado credor, isto é, eles funcionam como um credor que financia um devedor mesmo sabendo que ele não possui condições de quitar a dívida. E assim o faz porque precisa que o devedor continue comprando seus produtos e viabilizando seu modelo de crescimento baseado em exportações. É o tipo de solução biológica em que um organismo se especializa de tal forma no outro, que sua principal fonte de alimento é o outro. Nestes casos quando um organismo morre, ou definha, o outro também o faz. O esquema é insustentável, pois quanto mais o lado superavitário cresce, mais necessita que o outro lado se endivide e importe. E quanto mais o organismo credor cresce, mais sangue do organismo devedor necessita sugar para manter-se vivo, mas quanto mais sangue é cedido, mais debilitado fica o outro organismo.

Apesar do modelo de crescimento do capitalismo mundial estar em grande parte sustentado pelos elevados déficits americanos e europeus, o esquema dependeu dos dois lados. O lado devedor cresceu comprando barato e o lado credor cresceu industrializando-se a partir das exportações. Este esquema ajudou a enriquecer um mundo que antes era pobre, portanto, é injusta a acusação de que os países ditos industrializados são os únicos responsáveis pela crise financeira, sozinhos. Os países superavitários também se utilizaram favoravelmente do esquema. Seus modelos de crescimento baseado em superávit em transações correntes não teriam sido possíveis se não existissem países dispostos a operar

\footnotetext{
1 Charles Ponzi foi um italiano que emigrou para EUA em 1903 e agiu como um especulador financeiro americano, que montou um esquema milionário de pirâmide revendendo várias vezes um mesmo papel nos primeiros anos da década de 1920. Seu sobrenome virou adjetivo usado por economistas para caracterizar uma situação em que uma empresa, banco ou governo não tem condições suficientes para pagar os juros e a amortização de sua dívida, necessitando incorrer em mais dívida para quitar a dívida vencida.
} 
com elevados déficits. Numa relação comercial de comum acordo, não se pode culpar só um lado por um eventual mau negócio. É o caso. O padrão de crescimento econômico do ciclo de 1971-2010 viveu desta simbiose sino-americana e gerou externalidades para os demais países, especialmente os exportadores de commodities, que crescerem ao reboque do mundo, como o Brasil.

TABELA 1 - SALDO EM CONTA CORRENTE EM 2008 (US\$ BILLHÕES)

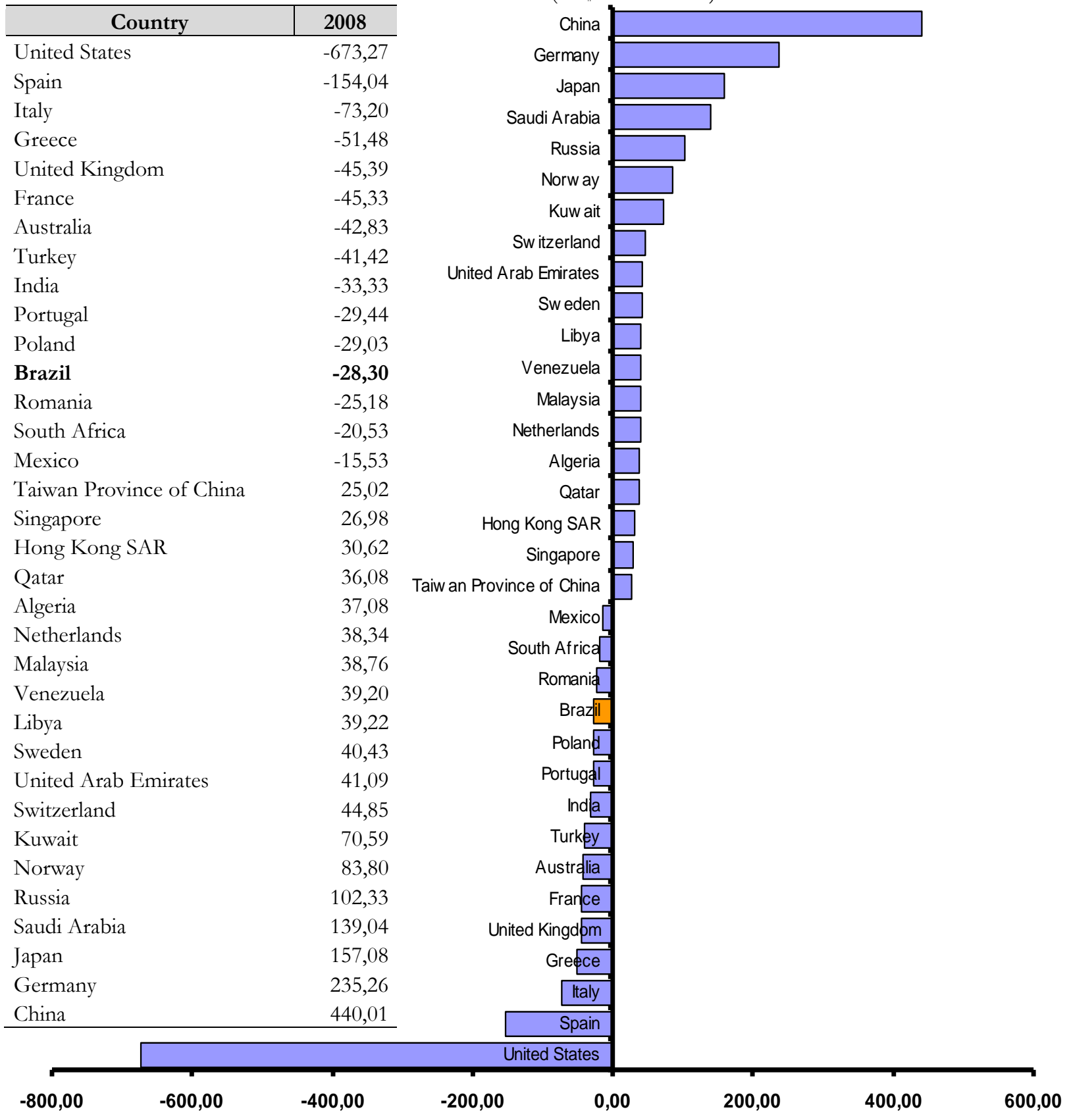

FONTE: International Monetary Fund - IMF.

A tabela 1 mostra quem são os principais países superavitários e deficitários que fazem parte do sistema binário. Como pode ser visto, em 2008 os cinco maiores superavitários foram, pela ordem China, Alemanha, Japão, Arábia Saudita e Rússia e os cinco maiores 
deficitários foram EUA, Espanha, Itália, Grécia e Reino Unido. Praticamente os principais países da Zona do Euro mais os americanos.

Uma das tendências inevitáveis para a economia do século XXI é a necessária correção deste grande desequilíbrio entre poupanças. Os países deficitários (que são praticamente os paises industrializados) deverão adotar políticas econômicas que reduzam e porventura até tornem seus balanços superavitários. Para isso duas grandes alternativas não excludentes e complementares estão à disposição e ambas já estão começando a serem implementadas. A primeira é forjar uma nova onda tecnológica que lhes permitam explorar vantagens comparativas tecnológicas dinâmicas por meio de ganhos de produtividade. A segunda é manter suas moedas desvalorizadas por um longo período.

As consequências disto, para uma economia de médio porte, no meio de um grande ajuste estrutural, como é o caso do Brasil, podem se revelar drásticas. O Brasil poderá ser espremido entre países desenvolvidos e suas novas estratégias e os países asiáticos, com sua atual capacidade competitiva dada por baixos salários e pela necessidade de substituir mercados no exterior, em função da redução das importações que deverá ocorrer no grupo de países deficitários.

\section{REESTRUTURAÇÃO PRODUTIVA E POLÍTICAS CAMBIAIS}

As evidências que sugerem que as políticas cambiais se complementem as políticas tecnológicas por meio ganhos de produtividade como forma de obter superávits ou evitar déficits nas balanças comerciais, podem ser observadas no gráfico 1 e na tabela 2 a seguir. $O$ caso do Brasil e do Euro é significativo.

O Brasil obteve um expressivo aumento do percentual de exportação de produtos de alta tecnologia em relação ao total de exportações do país, o qual aumentou de 6,1\% em 1996 para 19,6\% em 2001. O valor praticamente triplicou. Neste mesmo período o câmbio real desvalorizou-se de um índice real de 0,6 em 1996 para 1,2 em 2001, tomando-se como base o ano de 1987 quando o índice era igual a $1^{2}$. O aumento das exportações de alta tecnologia entre 1996 e 1999, durante a vigência do câmbio fixo - herança do Plano Real - deve-se em parte à política de abertura comercial adotada no período. Mas mesmo sob o regime de câmbio fixo (na verdade com flutuação administrada) o câmbio começou a se desvalorizar em 1998, por conta da exaustão das reservas internacionais que antecedeu o fim do regime de

\footnotetext{
2 O ano base de 1987, do gráfico 1 foi escolhido apenas para coincidir com a disponibilidade dos dados sobre percentual de exportações de alta tecnologia, disponíveis e apresentados na tabela 2.
} 
câmbio fixo. O efeito cambial potencializou os efeitos da política de abertura comercial levando a triplicar o percentual de exportações de alta tecnologia. O triênio de 2000-2003 combina a maior desvalorização do real observada no período com a maior participação das exportações de alta tecnologia no Brasil. Após 2002 o câmbio se valoriza, com o índice caindo de 1,2 para 0,6 aproximadamente, ao mesmo tempo em que as exportações de alta tecnologia diminuem de 19,2\% em 2001 para 12,8\% em 2007. As conquistas obtidas no triênio 20002003 foram perdidas nos anos seguintes por conta da valorização do Real.

GRÁFICO 1 - EVOLUÇÃO DA TAXA DE CÂMBIO REAL - JAN/1988=1,000

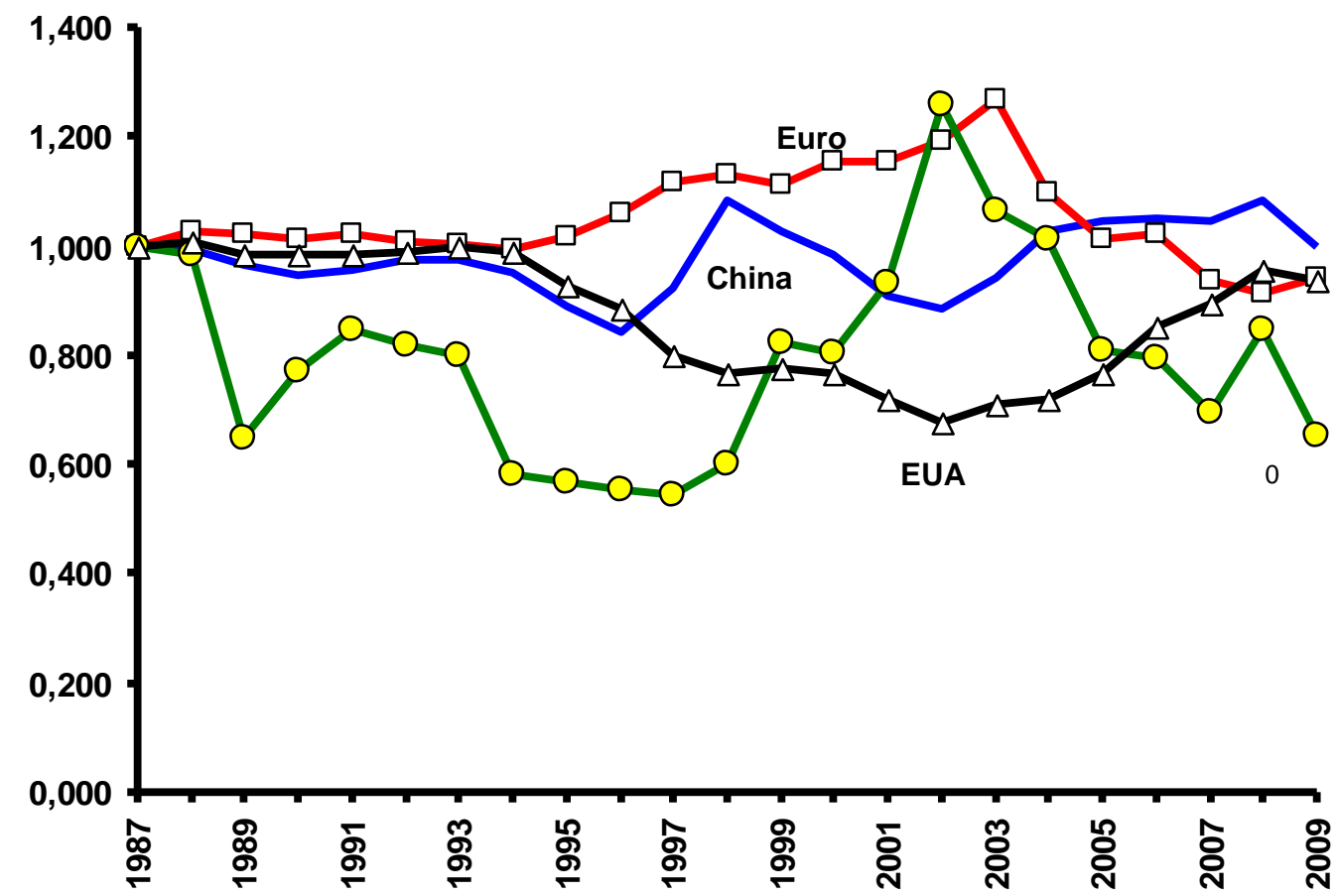

FONTE: BIS (EUA, China e Euro), BACEN (Brasil)

O caso do Euro também ilustra a correlação entre câmbio e exportações de alta tecnologia. As exportações da zona do Euro caíram de 19,5\% para 13,6\% entre 2001 e 2007, sendo que o câmbio se valoriza de 1,2 para 1,0 aproximadamente entre 2003 e 2007.

No caso da China o gráfico não mostra apropriadamente os movimentos mais ou menos sincronizados entre câmbio e exportação bigh-tech porque sua moeda já vem desvalorizada de um período antes de 1987. No entanto fica evidente que a China mantém sua moeda desvalorizada em relação ao dólar após 1996. Isto pode ser visto pela linha da China percorrendo o gráfico acima da linha americana. Se atentarmos para o fato de que os EUA são o principal destino das exportações chinesas fica também evidente que a elevação das exportações de 6\% em 1992 para 30\% em 2007 foi auxiliada pela manutenção do renminbi desvalorizado em relação ao dólar. Em termos relativos, ainda, a China manteve sua 
moeda como a mais desvalorizada entre os quatro casos analisados (sua linha é a mais alta de todas a partir de 2005).

TABELA 2 - HIGH-TECHNOLOGY EXPORTS ( \% OF MANUFACTURED EXPORTS)

\begin{tabular}{crr|r|r}
\hline Ano & Brasil & China & Euro & EUA \\
\hline 1988 & - & - & 11,54 & - \\
1989 & 6,48 & - & 11,94 & 32,69 \\
1990 & 7,09 & - & 12,05 & 33,04 \\
1991 & 5,67 & - & 13,12 & 32,94 \\
1992 & 5,37 & 6,11 & 13,16 & 33,16 \\
1993 & 4,14 & 6,84 & 14,36 & 31,90 \\
1994 & 4,76 & 7,95 & 14,39 & 31,49 \\
1995 & 4,86 & 10,05 & 14,75 & 30,56 \\
1996 & 6,12 & 12,02 & 15,04 & 30,98 \\
1997 & 7,35 & 12,69 & 15,95 & 31,68 \\
1998 & 9,23 & 15,06 & 16,99 & 33,08 \\
1999 & 13,07 & 16,77 & 17,55 & 34,07 \\
2000 & 18,72 & 18,57 & 19,49 & 33,40 \\
2001 & 19,26 & 20,56 & 18,88 & 32,32 \\
2002 & 17,02 & 23,30 & 17,25 & 31,53 \\
2003 & 12,08 & 27,09 & 16,66 & 30,55 \\
2004 & 11,70 & 29,79 & 16,66 & 30,07 \\
2005 & 12,97 & 30,59 & 16,78 & 29,79 \\
2006 & 12,29 & 30,28 & 16,32 & 29,96 \\
2007 & 12,38 & 29,69 & 13,67 & 28,41 \\
\hline
\end{tabular}

FONTE: World Bank: World Development Indicators WDI-2009.

Em termos de valorização relativa o caso do Brasil é oposto ao da China, apresentando a moeda mais valorizada entre as quatro analisadas. Considerando que EUA, Euro e China são os principais parceiros comerciais do Brasil, fica evidente a perda de capacidade competitiva do país.

Assim, no que se refere à tendência de ajuste macroeconômico, o que se espera é que a correção dos desequilíbrios dos países desenvolvidos (EUA e Europa) se faça gradativamente como já vêm ocorrendo de forma lenta e persistente nos EUA desde 2002, com desvalorização cambial da dupla renminbi e dólar, as duas linhas mais altas no gráfico. Neste caso o Brasil é duplamente enfraquecido no comercio internacional se confrontado com o EUA, que além da desvalorização relativa (comparado com o Real), ainda se dedica a implementar um amplo e ambicioso programa de aumento de produtividade e inauguração de uma nova onda tecnológica. O mesmo deverá fazer os países do Euro, especialmente os mais deficitários mostrados na tabela 1.

Os EUA, por exemplo, lançou o Recovery Act em 17 de fevereiro de 2009 e agora incluiu no pacote um programa de estimulo à inovação tecnológica de US\$100 bilhões onde deixa claro a adoção de uma política pública em três frentes destinada a construir pólos de 
inovação (Building Blocks of American Innovation) ${ }^{3}$, criar um ambiente nacional que fortaleça a capacidade das indústrias americanas em competir na economia global (Promote Competitive Markets that Spur Productive Entrepreneurship) e por fim alocar recursos em áreas previamente selecionadas (Catalyze Breakthroughs for National Priorities) (White House, 2009) ${ }^{4}$.

Por ambos os lados que se olhe, cambial e tecnológico, o Brasil estará espremido entre os movimentos das grandes economias e poderá ser prejudicado por ambos os lados (EUA e Emergentes) e por ambas políticas (cambial e tecnológica), a menos que o país possua coragem para ousar em suas próprias políticas tecnológicas e cambiais e mudar o atual regime macroeconômico que permite que o Real se valorize. O Brasil resgatará sua competitividade industrial diante de tão grandes ajustes, ou se converterá num exportador de commodities, e agora petróleo, empurrado para a "maldição das commodities" por leniência e timidez interna combinada com ousadia e determinação das demais nações?

\section{PORTFÓlIOS SOBERANOS E SUPERABUNDÂNCIA DE POUPANÇA GLOBAL}

O padrão de crescimento mundial do ciclo 1971-2010 produziu no final do ciclo o que Ben Bernanke chamou de "superabundância de poupança global". Esta superabundância foi criada a partir da acumulação de superávits na balança de pagamentos por parte do grupo de países superavitários a que nos referimos anteriormente. A poupança mundial é um conceito de difícil mensuração, e não há estatísticas a seu respeito. Por definição, em decorrência de procedimentos contábeis, a poupança global é igual ao investimento global. Assim o excesso de poupança mundial pode ser diagnosticado, aproximadamente, de três formas diferentes: i) indiretamente medindo-se o nível das taxas de juros reais, que refletem o preço do dinheiro ou poupança; ii) o saldo do setor privado entre poupanças e investimentos e iii) o saldo de diferentes países ou grupos de países. Dos três, o menos complexo é o terceiro. Uma questão importante ainda deve ser enfrentada: o que está sendo chamado de superabundância de poupança, pode ser na verdade uma insuficiência de investimento, pois de fato, os agentes econômicos tomam decisões sobre a destinação de sua renda entre,

\footnotetext{
${ }^{3}$ A noção de innovations blocks foi introduzida pelo economista sueco Erik Dahmen, que possui uma vasta obra sobre desenvolvimento econômico e inovação ainda pouco traduzida para o inglês. Dentre elas pode-se consultar Dahmen (1955) e o livro que trata da obra de Dahmen editado por Carlsson \& Henriksson (1991) com apoio do "Industrial Institute for Economic and Social Research.

${ }^{4}$ Ver http://www.whitehouse.gov/assets/documents/sept_20_innovation_whitepaper_final.pdf
} 
consumo, investimento e entesouramento (poupança), sendo que a decisão entre investir e poupar é uma só. Dadas as oportunidades da economia real, a decisão é sobre o investimento e não sobre a poupança diretamente. Esta decorre de uma identidade contábil. Assim, o problema da "abundância de poupança" pode ser analisado sobre a perspectiva de uma insuficiência de investimento diante de um estoque de poupança acumulada por um longo período por um grupo de países, na forma de reservas internacionais. Incapazes de investir todos os recursos poupados no setor real, os países superavitários precisam reciclar suas reservas. Eles fazem isso aplicando parte destas reservas no mercado financeiro causando uma baixa da taxa de juros real em nível internacional.

Este mecanismo está por detrás do modelo de crescimento mundial dos últimos anos que permitiu que o grupo de países superavitários persistisse em sua estratégia de industrialização, ao conseguirem reciclar suas reservas no sistema financeiro mundial evitando assim a valorização de suas moedas locais que seria causada pelo ingresso e conversão das divisas em moeda local. A tabela 3, a seguir, mostra os países que possuem os maiores estoques de reservas de divisas internacionais. Este montante, que não pode ser interpretado como sendo efetivamente uma medida de poupança, pode, no entanto, ser usado como uma proxy, na medida em que representa um excedente de recursos monetários não totalmente investidos no setor real da economia. O montante acumulado em 2009 chega a US\$ 8,465 trilhões de dólares, sendo que os 10 maiores países, excluindo as divisas do ECB, possuem US\$ 5,466 trilhões ou $65 \%$ do total.

Como boa parte destas reservas estão aplicadas em títulos públicos do governo americano e estão denominadas em dólar, os países credores podem vir a perder parte destas reservas caso a tendência de desvalorização do dólar na economia mundial, como mostrado na seção acima, se mantenha. Além disto, deve-se adicionar a elevação do risco país por parte da economia americana agravado pelo gigantesco custo fiscal de combate à crise, que poderá levar a dívida pública americana de $63,4 \%$ do $\mathrm{GNP}^{5}$ no pré-crise para inacreditáveis $88,8 \% \mathrm{em}$ 2009 e 112,0\% em 2014 (HORTON, 2009, IMF, appendix tabela 5). Haverá inevitavelmente uma fuga defensiva dos financiadores da economia americana. A tendência é que haja um ajuste gradativo ao longo do tempo e não um colapso repentino. No entanto a situação da economia americana é de grande instabilidade. Suas reservas internacionais são de apenas US\$ 83,375 bilhões, o que representa $1 / 3$ da reserva possuída pelo Brasil, de modo que a dependência de fluxos de capital financeiro é enorme. Um pequeno movimento de capitais

\footnotetext{
${ }^{5}$ Gross National Product.
} 
por parte dos fundos soberanos, no sentido de se desfazer do dólar, poderá levar ao colapso desta moeda. Sem incentivos econômicos para que os fundos soberanos mantenham parte de seus recursos em moeda americana, o equilíbrio mundial na fase de transição somente poderá ser mantido mediante acordos políticos entre países e seus bancos centrais.

TABELA 3 - RESERVAS EM MOEDA ESTRANGEIRA

\begin{tabular}{clrr}
\hline Rank & \multicolumn{1}{c|}{ Country/Monetary Authority } & \multicolumn{1}{c}{ USD } & \multicolumn{1}{c}{ Date } \\
\hline 1 & People's Republic of China (Mainland China only) & 2.131 .600 & Jun 2009 \\
2 & Japan & 1.044 .327 & Jul 2009 \\
$*$ & EU member states which have adopted the euro, incl. ECB ${ }^{1}$ & 539.219 & Apr 2009 \\
3 & Russia & 412.590 & Jul 2009 \\
4 & Saudi Arabia & 395.467 & May 2009 \\
5 & Republic of China (Taiwan) & 325.417 & Aug 2009 \\
6 & India & 280.978 & Sep 2009 \\
7 & South Korea & 245.460 & Aug 2009 \\
$\mathbf{8}$ & Brazil & $\mathbf{2 2 3 . 6 8 1}$ & Sep 2009 \\
9 & Hong Kong & 223.300 & Aug 2009 \\
10 & Germany & 184.167 & Jul 2009 \\
11 & Singapore & 173.191 & Jun 2009 \\
12 & Switzerland & 160.166 & Jul 2009 \\
13 & Algeria & 145.363 & Apr 2009 \\
14 & France & 130.094 & Jul 2009 \\
15 & Thailand & 125.100 & Jul 2009 \\
16 & Italy & 112.967 & Jul 2009 \\
17 & Iran & 96.560 & Dec 2008 \\
18 & Malaysia & 91.400 & Aug 2009 \\
19 & United Kingdom & 83.935 & Aug 2009 \\
20 & United States & 83.375 & Jul 2009 \\
--- Demais (136 países) & & \\
& World (sum of all countries) & $\mathbf{1 . 8 3 8 . 6 4 1}$ & \\
\hline
\end{tabular}

FONTE: International Monetary Fund - IMF

1. European Central Bank. Para evitar dupla contagem o valor consta na tabela, mas não é somado no total mundial, uma vez que estas reservas pertencem a países da União Européia.

2. A maioria dos países possuem dados atualizado até abr-jul/2009. Alguns, como Venezuela e Servia, apresentam dados desatualizados, do ano de 2008.

\section{ESTADO E ECONOMIA}

Do ponto de vista político, o ciclo de crescimento 1971-2010 é considerado como um período marcado pelo retorno do liberalismo econômico. Mas esta noção sobre o predomínio do neoliberalismo não é de todo correta. O Estado moderno, pós-revolução industrial, sempre desempenhou um papel chave e complementar na economia arbitrando a acumulação de capital através de uma organização fluída do governo (este como uma concretização da idéia de Estado) com o objetivo de sustentar o crescimento econômico. A participação do Estado sempre foi fundamental à organização do sistema capitalista. A depender do padrão do ciclo de crescimento econômico, o governo assume tarefas próprias às necessidades de cada época, como Estado de Bem Estar Social, Estado-produtor ou simplesmente como regulador à distância. No fundo da crise econômica de 2008-2010, o 
Estado é chamado de volta à cena como "Instituição de Última Instância" do sistema capitalista (PEREIMA \& AQUINO, 2009).

Neste ciclo 1971-2010, o Estado sempre esteve presente, através de elevadas relações entre orçamento/PIB nos principais países, inclusive nos ditos países liberais como EUA e Reino Unido. Isto ocorreu mesmo quando os governos liberais "devolveram ao mercado" a gestão dos interesses econômicos. Mas ao mesmo tempo em que implementaram programas de privatização de atividades e serviços públicos e redução da regulação econômica, mantiveram os orçamentos públicos elevados. No caso dos países orientais, mesmo os países asiáticos que implementaram amplas reformas capitalistas, o papel ativo do Estado foi fundamental. Sem o Estado por detrás dos amplos modelos de desenvolvimento baseado em exportação, seria impossível conceber o crescimento observado nos países asiáticos e mesmo nos países ocidentais. Foi o Estado oriental, nas suas diversas formas idiossincráticas que vai do comunismo chinês à democracia parlamentar do Japão, em última instância, quem forjou uma economia capitalista superavitária por parte do Japão, Asiáticos e Alemanha (esta com menos intensidade Estatal comparada aos demais asiáticos) e foi o Estado dos países deficitários, especialmente EUA e Reino Unido quem garantiu a reciclagem das poupanças externas dos países superavitários em transações (tabela 1), dando sustentação ao crescimento econômico da relação simbiótica sino-americana.

A crise financeira de 2007-2009 abriu um caminho duplo para uma reorientação do papel do Estado na regulação da economia capitalista. O primeiro caminho foi que a crise mostrou a necessidade de políticas keynesianas de redução de tributos e aumento de gastos como alternativa de curto prazo para salvar as economias pelo lado da demanda efetiva, acrescido de política monetária expansionista na forma de injeção de liquidez e redução de juros e na forma de garantia institucional ao sistema financeiro. O segundo caminho é a destruição dos argumentos políticos apoiados na teoria econômica da eficiência dos mercados livres e não regulados. A tendência, para o século XXI é um maior consenso nos países em geral, de que o Estado é uma instituição importante na regulação da economia capitalista e que ele deverá desempenhar um papel chave na dinâmica competitiva entre as nações.

Num primeiro momento, a competição internacional entre países, especialmente entre os industrializados tende a recrudescer, pois eles serão pressionados politicamente por suas populações para resolver o imenso desemprego deixado pela crise. Mecanismos de colaboração internacional somente tenderão a retornar após a restauração dos empregos locais. 


\section{O BRASIL NO SÉCULO XXI, DESAFIOS E POSSIBILIDADES}

Diante de grandes mudanças em curso na economia mundial o Brasil não pode se dar ao luxo e ignorância de que meias medidas adaptativas serão suficientes para torná-lo uma economia competitiva e tecnologicamente avançada no mundo. Se permanecer a atual leniência e timidez das políticas estruturantes, o mediano avanço absoluto que o país poderá obter, quando comparado a si mesmo, poderá na verdade significar retrocesso quando comparado ao resto do mundo, especialmente em relação aos países desenvolvidos e aos demais países emergentes.

Para que isso fique mais claro, podemos pensar em termos de combinação entre política cambial e tecnológica. A política cambial e tecnológica do Brasil, historicamente após os anos 1970, não caminham no mesmo sentido. O câmbio sempre foi um instrumento de política macroeconômica de curto prazo, e não um instrumento de industrialização e estimulo ao avanço tecnológico. Isto é o contrário do que ocorreu com os países asiáticos e o contrário do que está ocorrendo com a economia americana a partir de 2009 (como mostrado no gráfico 1). No passado recente os asiáticos combinaram de forma consistente política cambial e tecnológica. Agora os EUA, fazem a mesma coisa, como estratégia de emergir da crise através da emenda orçamentária de alocação de US $\$ 100$ bilhões ao Recovery Act e ao plano estratégico de inovação tecnológica que fará uso destes recursos.

Enquanto isso o Brasil persiste, a passos lentos, se comparado ao resto do mundo, com sua política econômica contraditória, onde o avanço lento da Política Nacional de Ciência, Tecnologia e Inovação encontra restrição forte na política cambial dominada por razões de curto prazo de ordem macroeconômica.

O Brasil corre um risco de ficar espremido entre os movimentos agressivos e ousados dos países industrializados e emergentes, que buscam recuperar suas capacidades competitivas (industrializados) ou manter seu ritmo frenético de crescimento e catchin-up tecnológico (emergentes).

\section{REFERÊNCIAS}

CARLSSON, BO \& HENRIKSSON, ROLF G.H... Development Blocks and Industrial Transformation: The Dahmenian Approach to Economic Development. The Industrial Institute for Economic and Social Research, Stockholm.

INTERNATIONAL ECONOMIC ASSOCIATION, 1955, Conference in Santa Margherita, Ligure, Italy . Technology, Innovation and International Industrial Transformatation. 
HORTON, MARK, et alli, 2009. The State of Public Finances: A Cross-Country Fiscal Monitor, IMF Staff Position Note, jul 30, 2009, spn/09/21.

IMF; (2009). World Economic Outlook, apr-2009.

ENCONTRO DE ECONOMIA POLÍTICA, 14, 2009, São Paulo. Estado e crise no capitalismo: a instituição de última instância. São Paulo, 2009.

White House; (2009). Disponível em: http://www.whitehouse.gov/assets/documents/ sept_20_innovation_whitepaper_final.pdf. 
